Rev. Biol. Trop., 47(1-2): 271-272, 1999

www.ucr.ac.cr www.ots.ac.cr www.ots.duke.edu

\title{
Reproduction and dental age classes of the little water opossum (Lutreolina crassicaudata) in Buenos Aires, Argentina
}

\author{
Héctor A. Regidor, Martín Gorostiague and Silvia Sühring \\ Facultad de Ciencias Naturales, Universidad Nacional de Salta, Buenos Aires 177 (4400) Salta, Argentina. E-mail: \\ ecologiaunsa.edu.ar.
}

Received 20-VI-1998. Corrected 18-XI-1998. Accepted 27-XI-1998

Key words: Lutreolina crassicaudata, reproduction, breeding season, dental age class.

The little water or red opossum (Lutreolina crassicaudata) is one of least studied didelphid marsupial species (Redford and Eisenberg 1992). The long weasel-like body, short legs, small and rounded ears, and reddish brown fur are this opossum distinctive characteristics. Nocturnal and crepuscular, it is common near areas of permanent water, feeding on small mammals, birds, insects and aquatic invertebrates. This note documents reproductive patterns near the southern limits of their distribution.

Thirty-six specimens were live-trapped from September 1990 to July 1991 in a field of 135 ha crossed by El Gato stream and several brooklets, that was utilized to cultivate tomato thirteen years ago, located in a rural zone about $50 \mathrm{~km}$ south of Buenos Aires, Argentina. Opossums were toe-clipped, weighted, sexed and assigned to one of 5 dental classes based on the sequence of tooth eruption of the postcanine cheekteeth (Regidor \& Gorostiague 1990). They were subsequently released. Ages determined were related to the reproductive cycle of $L$. crassicaudata. Thirty-three recaptures corroborated the age class designation. We considered the reproductive season as from first mating to weaning of the last litter. The pouch condition of all females and litter size were recorded. If external sex organs were evident, pouch young sex was recorded.

The sequence of tooth eruption was a useful indicator of age from weaning to the adult condition, attained after 6 months of life (Table 1). Deciduous first molars $M^{1}$ characterized juvenile age classes; third premolars $\mathrm{P}^{3}$, the subadult class, and the complete permanent dentition $\mathrm{P}^{1-3} \mathrm{M}^{2-5}$, the adult ones.

Breeding began in September after an anestrous period of 5 months and finished by early April. All members of the population were in breeding condition at the onset of reproductive season. The male to female ratio was $23: 13$. It was significantly different from the expected value of $1: 1\left(\mathrm{X}^{2}=2.210, \mathrm{P}=0.1336\right)$. Adult males were heavier than adult females (XSD: $790.54 \pm 138.73$ and $522.00 \pm 111.54, \mathrm{n}$ $=37$ and 18 respectively, $\mathrm{t}=6.66, \mathrm{P}<0.001$ ).

Two breeding periods were apparent based on the estimated date of birth and weaning. The first litters were born in late September and second litters were produced in late December or early January. We trapped 4 females with pouch young. Of these, only 1 nursing female, trapped and released in October 1990, was recaptured in early March with new pouch young about 2.5 months old. 
Litter size ranged from 7 to 11 ( $\bar{X}=8.6$ $1.52, \pm \mathrm{n}=5$ ). The sex ratio in the pouch was20:15 males to females, and not significantly different from the expected ratio of 1:1 $(\bar{X}=0.457, P=0.499)$. As litters were born mainly in September and December and weanlings first trapped in late December and late March, we concluded that young opossums had been weaned at about three months age. Since sexual maturity is reached at 6 or more months, juveniles probably do not reproduce until the next breeding season.

\section{REFERENCES}

Redford, K. \& J. Eisenberg, 1992. Mammals of the Neotropics, The Southern Cone, Vol. II, Univ. Chicago Press.

Regidor, H. A. \& M. Gorostiague. 1990. Age determination in the white-eared opossum (Didelphis albiventris). Vida Silv. Neotr. 2: 75-76. 